\title{
Stability-indicating ultra-fast liquid chromatographic analysis of maprotiline in pharmaceutical formulations
}

\author{
Cem Önal ${ }^{1 *}$ and Ş. Evrim Kepekçi Tekkeli@2 \\ ${ }^{1}$ CinnaGen Pharmaceutical Atasehir/Istanbul, Türkiye \\ ${ }^{2}$ Faculty of Pharmacy, Department of Analytical Chemistry, Bezmialem Vakif University, Fatih, \\ Istanbul, Türkiye
}

(Received July 24, 2019; Revised October 05, 2019; Accepted October 11, 2019)

\begin{abstract}
This current study aimed to develop a simple, fast, and reproducible isocratic reverse-phase ultra-fast liquid chromatographic (RP-UFLC) method to detect and quantify maprotiline hydrochloride (MAP) in bulk drug and pharmaceutical formulations. Chromatographic separation was accomplished on a C18 column $(100 \times$ $4 \mathrm{~mm}, 3 \mu \mathrm{m})$ under isocratic elution with the use of a binary solution of acetonitrile and phosphate buffer at a $\mathrm{pH}$ of $7(75: 25, \mathrm{v} / \mathrm{v})$ and a flow rate of $0.4 \mathrm{~mL}$ per minute at $215 \mathrm{~nm}$. The linearity was excellent in the concentration range of MAP from 0.1 to $1.5 \mu \mathrm{g} / \mathrm{mL}$ with a regression coefficient of 0.9996 . The proposed method was validated with the respective ICH guidelines. The drug was subjected to hydrolytic, acidic, basic, thermal, photolytic, and oxidative stress conditions as required by the ICH regulation. The method was found to be suitable for use in routine practice to analyze MAP in the pharmaceutical dosage form.
\end{abstract}

Keywords: Maprotiline; UFLC; method validation; stability indicating; tablets; quality control. (C) 2019 ACG Publications. All rights reserved.

\section{Sample Source}

Maprotiline, 1-(3-methylaminopropyl) dibenzo(b,e) bicyclo (2.2.2) octadiene, is a tetracyclic drug, distinguished from conventional tricyclic antidepressants only by the rigid flexure of its molecular skeleton [1].

\section{Previous Studies}

Several methods for the determination of maprotiline in biological samples or pharmaceutical preparation have been published. There is only one stability indicating HPLC method for the determination of MAP [2].

\section{Present study}

In our study, we developed ultra fast liquid chromatographic (UFLC) method for the determination of MAP in bulk and tablets preparation. The UFLC method offers benefits as an alternative to conventional HPLC. It not only reduces the period required to complete the analyses and conserves the solvent used for the process but it also allows for separating and determining the dug

\footnotetext{
${ }^{*}$ Corresponding author: cemfox@yahoo.com
} 
substance reliably in pharmaceutical formulation. These advantages of the UFLC method provides increased efficiency of the analysis [3-5].

This study demonstrated that the proposed method was successfully validated according to the International Conference Harmonization (ICH) guidelines [6]. To be able to separate the drug product the following method was developed and validated accordingly.

Instrumentation and chromatographic conditions: The chromatographic separations were performed on a Shimadzu LC 20A UFLC (Shimadzu, Kyoto, Japan). A system was consisted of LC 20AB Binary pump, SIL 20AC Autosampler, CTO-10As column oven, and SPD M20A photodiode array (PDA) detector. Chromatographic data were collected and computed by LC Solution system software. Chromatographic separation was achieved on a Inertsustain C18 column $(4.0 \times 100 \mathrm{~mm}, 3 \mu \mathrm{m})$ (GL Sciences, Tokyo-JAPAN) under isocratic elution with acetonitrile and phosphate buffer buffer of $\mathrm{pH}: 7$ $(75: 25, \mathrm{v} / \mathrm{v})$, at a flow rate of $0.4 \mathrm{~mL}$ per minute. The detection was carried out at $215 \mathrm{~nm}$ and the column temperature was set at $25^{\circ} \mathrm{C}$. The $\mathrm{pH}$ was measured by WTW $\mathrm{pH} 526$ digital pH meter (Mettler Toledo, Germany). Figure 1 shows the typical chromatograms of MAP during this current study ( see supporting information for details).

(A)

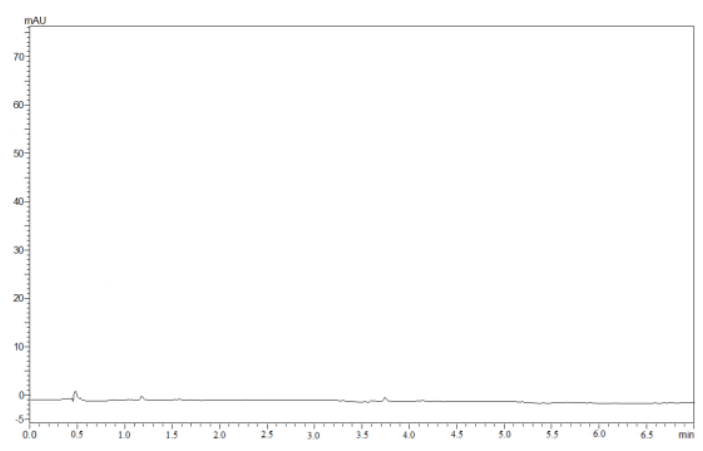

(B)

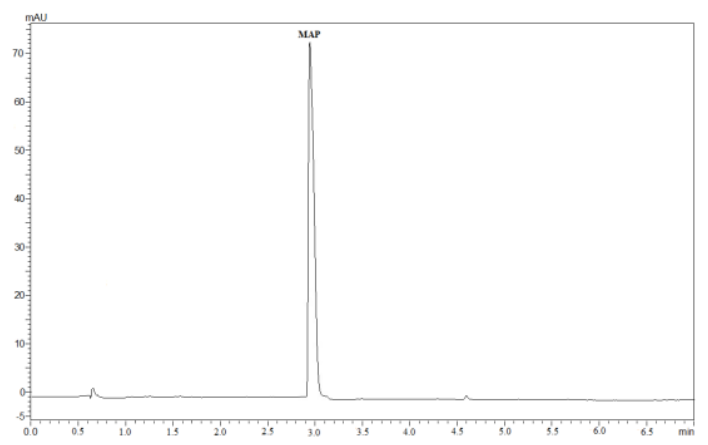

Figure 1. Representative chromatograms of (A) blank, (B) MAP $(1.0 \mu \mathrm{g} / \mathrm{mL}$ concentration)

Method Validation: The validation parameters were determined to be linearity, accuracy, precision sensitivity, robustness, limit of detection (LOD), and limit of quantification (LOQ) experiments. The linearity of compound was determined by analyzing standard solutions. The correlation coefficients $\left(\mathrm{R}^{2}\right)$ were found to be $\geq 0.99$. The validation parameters are summarized Table 1 and detailed in supporting information. The procedures of method validation and uncertainty evaluation are available in ICH Guidelines [6-8].

Forced degradation samples produced by exposing the samples to the above mentioned conditions were analyzed at an initial concentration of $1 \mu \mathrm{g} / \mathrm{mL}$. A PDA detector was used to ensure the homogeneity of the MAP peaks. The acidic hydrolysis $\left(0.1 \mathrm{~N} \mathrm{HCl}\right.$ at $80^{\circ} \mathrm{C}$ for 4 hours $)$ resulted in $25.65 \%$ degradation and basic hydrolysis $\left(0.1 \mathrm{~N} \mathrm{NaOH}\right.$ at $80^{\circ} \mathrm{C}$ for 4 hours) resulted in $12.24 \%$ degradation. After the peroxide degradation (using 3\% $\mathrm{H}_{2} \mathrm{O}_{2}$ at room temperature for 4 hours), a degradation of about $17.16 \%$ was observed. MAP was found to be favorably stable under neutral, photolytic (exposure to sunlight for 24 hours), and thermal $\left(105^{\circ} \mathrm{C}\right.$ for 4 hours) conditions. However, the present study revealed that the drug was sensitive to acid, base, and oxidative hydrolysis. The proposed method was capable of separating degradation products in the presence of MAP. The analytes were well-separated and the degradation peaks were obtained at the end of all degradation experiments (see supporting information Table S2 and Figure S1). 
Characteristic parameters for regression equation observed during the course of validation are given in Table 1. The precision studies were carried out for a period of five consecutive days by analyzing the quantity of MAP (each $n=5$ ). The RSD values were found to be $0.54 \%$ for intra-day precision and they were in the range of $0.69 \%$ for inter-day precision. All these values were below $2 \%$, confirming that the method was precise. The results of the tests have been shown in Table 1.

Table 1. Some validation parameters.

\begin{tabular}{ll}
\hline Parameters & Values \\
\hline Regression equation & $\mathrm{y}=778018 \mathrm{x}-62982$ \\
Slope & 778018 \\
Intercept & -62982 \\
Correlation coefficient & 0.9996 \\
Linearity range & $0.1-1.5$ \\
$(\mu \mathrm{g} / \mathrm{mL})^{\mathrm{b}}$ & \\
LOD $(\mu \mathrm{g} / \mathrm{mL})$ & 0.048 \\
LOQ $(\mu \mathrm{g} / \mathrm{mL})$ & 0.15 \\
Intraday precision $(\mathrm{RSD})^{\mathrm{c}}$ & 0.54 \\
Interday Precision $(\mathrm{RSD})^{\mathrm{c}}$ & 0.69 \\
\hline${ }^{\mathrm{a}}$ Average of five determinatons & \\
${ }^{\mathrm{b}} \mathrm{n}=5$ & \\
${ }^{\mathrm{c}}$ Results of five different days &
\end{tabular}

The standard addition technique was carried out to prove the accuracy of the proposed method. Before the analysis, a pre-determined amount $(1 \mu \mathrm{g} / \mathrm{mL})$ of pure sample solution was added to the standar solutions of MAP at the respective concentrations of $0.1,0.5,1.0 \mu \mathrm{g} / \mathrm{mL}$. The percentage recoveries for the drug and impurities were noted within the range from $99.33 \%$ to $101.20 \%$.

Robustness was evaluated for $1.0 \mu \mathrm{g} / \mathrm{mL}$ concentration $(\mathrm{n}=3)$. It was observed in this present study that all of the analyte peaks were adequately resolved and the order elution did not change in all of the deliberate variations of the chromatographic conditions including the flow rate $( \pm 0.1 \mathrm{~mL} / \mathrm{min})$, column temperature $\left(25 \pm 5^{\circ} \mathrm{C}\right)$, mobile phase $\mathrm{pH}$ variation $(7.0 \pm 0.2)$, and organic phase composition $( \pm 2 \%)$ ]. The study has demonstrated that the proposed method is robust.

The proposed method was used for the quantitation of MAP in the tablet formulation. The validity of the proposed method was assessed by statistically comparing the spectrophotometric study results reported in the literature [7] with those found for the proposed method in this present study. The student's t-test was performed for accuracy and F-test was used for precision in some commercial formulations. The results of the statistical analyses are shown in Table 2. The t- and F-values at the 95\% confidence level did not exceed the tabulated values, further confirming that there were no significant differences in accuracy and precision between the reference and proposed methods.

Table 2. Determination of MAP in tablets by the proposed methods $(n=5)$

\begin{tabular}{ccccccc}
\hline $\begin{array}{c}\text { Label claim } \\
(\mathrm{mg} / \text { per } \\
\text { tablet })\end{array}$ & $\begin{array}{c}\text { Reference method } \\
\text { Recovery }(\%) \\
\text { Mean }^{\mathrm{b}} \pm \mathrm{S}^{\mathrm{c}} \mathrm{D}^{\mathrm{c}}\end{array}$ & $\begin{array}{c}\text { RSD } \\
(\%)\end{array}$ & $\begin{array}{c}\text { Proposed Method } \\
\text { Recovery }(\%) \\
\text { Mean }^{\mathrm{b}} \pm \mathrm{S}^{\mathrm{C}} \mathrm{D}^{\mathrm{c}}\end{array}$ & $\begin{array}{c}\text { RSD } \\
(\%)\end{array}$ & t-value & F-value \\
\hline 25 & $99.36 \pm 0.28$ & 0.28 & $99.94 \pm 0.24$ & 0.24 & 2.006 & 4.069 \\
\hline
\end{tabular}

${ }^{\text {a}}$ Ludiomil Tablet $®(25 \mathrm{mg})$

${ }^{\mathrm{b}}$ Five independent analyses.

'Standard deviation

Tabulated t-value at $95 \%$ confidence level is 2.78 ; tabulatedF-value at $95 \%$ confidence level is 6.39 
In conclusion, A RP-UFLC method presented in this article was developed for carrying out quantitative analyses of MAP in pharmaceutical dosage forms. The UFLC method superior to conventional HPLC method in terms of reduces the period required to complete the analyses and conserves the solvent used for the process [3-5]. The drug product MAP in this study was found to be stable under basic, thermal, and photolytic conditions; however, it degraded in acidic, hydrolytic, and oxidative stress conditions. The stress test results obtained in this present study demonstrate that it is a stability-indicating method, which will allow for appropriate and fast analysis of maprotiline hydrochloride in bulk drug and dosage forms.

\section{ORCID}

Cem Önal: 0000-0002-5840-7386

Ş. Evrim Kepekçi Tekkeli: 0000-0002-1871-017X

\section{References}

[1] R. M. Pinder, R.N. Brogden, T.M. Speight and G.S. Avery (1997). Maprotiline: a review of its pharmacological properties and therapeutic efficacy in mental depressive states. Drugs 13(5), 321-52.

[2] L.j. Duric, Svetlana, C. Naskovic, Daniela, T.Velickovic, Dragan and M. Dragan Milenovic (2015). Development and validation of stability indicating chromatographic method for determination of impurities in maprotiline pharmaceutical tablets, J. Anal. Chem. 70 (2), 225 233.

[3] B. R. Gangadasu, G. Nagarjuna Reddy and K. Dhanalakshmi (2015). Comparison of UPLC with UFLC: Liquid Chromatography, Int. J. Pharm. Sci. Rev. Res. 31(1), 20, 97-101.

[4] S.S. Panda B.V. Ravi Kumar G. Mohanta R. Dash and P.K. Patel (2012). New stabilityindicating RP-UFLC method for determination of trospium chloride in tablet dosage form. Sci Pharm. 80(4), 955-964.

[5] F.S. Bandarkar and I.S. Khattab (2010). Simultaneous estimation of glibenclamide, gliclazide, and metformin hydrochloride from bulk and commercial products using a validated ultra fast liquid chromatography technique. J. Liq. Chromatogr. Relat. Technol. 33, 1814-1830.

[6] ICH, "Q2 (R1) (2005) Validation of Analytical Procedures: Text and Methodology," International Conference on Harmonization, Geneva, November 1-13.

[7] S.E. Kepecki and A. Oztunc (2005). Determination of maprotiline hydrochloride by ion-pair extraction using bromophenol blue and bromocresol purple, Acta Pharm. Turc. 47, 65-73

[8] H O. Hamad, M. H. Alma, İ. Gulcin, M. A. Yılmaz and E. Karaoğul (2017)Evaluation of phenolic contents and bioactivity of root and nutgall extracts from Iraqian Quercus infectoria Olivier, Rec.Nat. Prod. 11(2), 205-210.

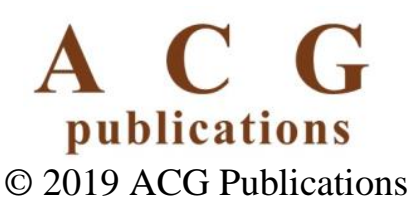

